\title{
EKSPERIMENTASI MODEL PEMBELAJARAN JIGSAW PUZZLE MAP TERHADAP PRESTASI BELAJAR MATEMATIKA MATERI HIMPUNAN DITINJAU DARI TIPE KEPRIBADIAN SISWA KELAS VII SEMESTER 1 MTsN 1 BOJONEGORO TAHUN AJARAN 2015/2016
}

\author{
Anis Umi Khoirotunnisa' \\ Program Studi Pendidikan Matematika, FPMIPA, IKIP PGRI Bojonegoro \\ e-mail: anis.umiikippgribojonegoro@gmail.com
}

\begin{abstract}
The research was conducted with the aim to determine: (1) which one results better mathermatics learning achievements between Jigsaw puzzle map and conventional learning model, (2) wich one results better mathematics learning achievements student with rational personality type, idealist personality type, guardian personality type, and artisan personality type in solving mathematics problems, (3) whether there is an interaction between learning model and the type of personality to the mathematics achievement of students.it was quantitative with quasi experimental research. The subject of this research was taken by using a cluster random sampling. The subject of this research 70 student of the seven grade whom come from 2 class students at MTsN I Bojonegoro. The techniques of collecting the data in this research were questionnaire and written test. The result of this eksperiment is : (1) jigsaw puzzle map learning model are better than convenstional learning model. (2) personality type give effect in mathematics learning achievements student, (3) there is no interaction between learning model ang the type of personality to the mathematics achievent students.
\end{abstract}

Keywords:Jigsaw; Puzzle Map; Personality Type; Learning Achievement

Abstrak:Penelitian ini bertujuan untuk mengetahui: (1) manakah yang menghasilkan prestasi belajar yang lebih baik antara model pembelajaran jigsaw puzzle map dan konvensional.(2) manakah yang prestasi belajarnya lebih baik siswa dengan tipe kepribadian rasional,idealis, guardian, dan artisan, (3) apakah terdapat interaksi antara model pembelajaran dengan tipe kepribadian pada prestasi belajar matematika. Penelitian ini merupakan penetian eksperimental semu. Subject dalam penelitan ini adalah 70 siswa yang terdiri dari dua kelas di MTsN Bojonegoro. Teknik pengambilan data dalam penelitian ini menggunakan tes tertulis dan angket. Hasil dari penelitian menyatakan bahwa: (1) pembelajaran jigsaw puzzle map memberikan prestasi belajar matematika lebih baik dibandingkan pembelajaran konvensional. (2) Tipe Kepribadian mempengaruhi prestasi belajar matematika siswa, (3). Tidak terdapat interaksi antara model pembelajaran dengan tipe kerpribadian siswa.

Kata Kunci: Jigsaw; Puzzle Map; Tipe Kepribadian; Prestasi Belajar

\section{PENDAHULUAN}

Fakta sejarah menunjukkan bahwa perubahan suatu bangsa hanya dimungkinkan ketika sumber daya manusianya senantiasa berubah dan berkembang mengikuti perkembangan. Pengembangan manusia dapat terwujud melalui sebuah proses pendidikan. Keharusan untuk menyelenggarakan proses pendidikan yang baik telah tertuang dalam Undang-Undang Dasar 1945. Dalam rangka melaksanakan dan mengaktualsasikan pesan UndangUndang, pemerintah menyediakan perang- 
kat institusi untuk merencanakan dan melaksanakan program-program pendidikan nasional yaitu departemen pendidikan. Pembangunan pendidikan diarahkan untuk menghasilkan Indonesia yang cerdas dan kompetitif melalui peningkatan ketersediaan, keterjangkauan, kualitas dan relevansi, kesetaraan dan kepastian memperoleh pendidikan. Peningkatan kualitas pendidik dan tenaga kependidikan, mewajibkan para guru untuk memiliki kualifikasi akademik, kompetensi, sertifikat pendidik, sehat jasmani dan rohani serta memiliki kemampuan untuk mewujudkan tujuan pendidikan nasional. Peningkatan akses dan kualitas pendidikan menengah umum dan relevansi pendidikan menjadi fokus utama dalam pembangunan pendidikan di Indonesia.

Matematika merupakan salah satu ilmu yang mendasari perkembangan ilmu pengetahuan dan teknologi serta mempunyai peran yang sangat sentral dalam pengembangan kemampuan berpikir dan bekerjasama sehingga mereka siap menghadapi segala bidang kehidupan. Hal ini sejalan dengan penjelasan BNSP (2006: 416) bahwa mata pelajaran matematika diberikan kepada semua peserta didik mulai dari sekolah dasar hingga menengah untuk memberi bekal peserta didik berkemampuan berpikir logis, analitis, sistematis, kritis dan kreatif dan kemampuan bekerjasama.

Hasil Trends in International Mathematics and Science Study (TIMMS) 2011 menempatkan indonesia pada posisi rendah survey tersebut. Sebagaimana yang dituliskan Elin Driana (Kompas, 14/12/2012) peringkat Indonesia bahkan berada dibawah Palestina. Sekitar separuh peserta Indonesia tidak mencapai standart terendah TIMSS 2011, yaitu sekitar 46\% untuk Sains dan sekitar 57\% untuk matematika.

Prestasi relative lebih buruk pada Programme for International Student Assessment (PISA) yang dipublikasikan the Organization for Economic Cooperation and Development (OECD) yang dimuat dalam Kompas (5 Desember 2013) menyatakan bahwa Indonesia hanya sedikit lebih baik dari Peru yang berada di ranking terbawah. Rata-rata skor matematika anakanak Indonesia 375, rata-rata skor membaca 396, dan rata-rata skor untuk sains 382. Padahal, rata-rata skor OECD secara berurutan adalah 494, 496 dan 501. Hal ini menunjukkan bahwa pendidikan di Indonesia membutuhkan penanganan yang serius, tidak hanya dalam hal pembangunan sarana dan prasarana penunjang namun lebih penting lagi adalah upaya meningkatkan daya serap siswa dalam proses pembelajaran.

Rendahnya proporsi masyarakat yang mengusai sains dan matematika dengan baik berarti tidak tersedianya cukup sumberdaya dengan keahlian memadai untuk mengembangkan sains dan teknologi. Selain itu, isu-isu sains dan teknologi tidak laku di masyarakat. Penyelenggara Negara, baik legislative maupun eksekutif, tidak memiliki kapasitas cukup untuk mengambil keputusan terkait sains dan teknologi. Hal tersebut menyulitkan kita untuk meraih kemandirian dalam sains dan teknologi. Industry yang berbasiskan teknologi tinggi tidak berkembang dan pada akhirnya Indonesia akan menjadi konsumen semata di pasar teknologi dunia.

Matematika merupakan salah satu bidang ilmu yang masih ditakuti dan dianggap sulit oleh siswa. Beberapa materi pada matematika seringkali dianggap sulit dipahami karena guru hanya menjelaskan berdasarkan apa yang tertulis di buku teks 
namun tidak mengaitkanya dengan contoh pada kehidupan sehari-hari siswa. Seperti yang dikemukakan Shields dalam Whyte\& Anthony (2012: 8) bahwaWhile traditional instruction may contribute to maths anxiety, so too does the culture of the classroom. Classroom culture can be defined as the behaviours and norms that guide classroom interactions. Experiences of learning mathematics in structured, rigid classrooms include little opportunity for debate or discussion, focus on searching for the one right answer, offer limited encouragement to reflect on thinking, expect quick answers and emphasise time test

Salah seorang guru mata pelajaran Matematika mengemukakan bahwa siswa sering mengalami kesulitan dalam menyelesaikan soal-soal pada pokok bahasan himpunan khususnya siswa sering mengalami kesulitan dalam menyelesaikan soal-soal yang menyangkut operasi himpunan, sehingga seringkali diadakan pengajaran remedial setelah diadakan kuis atau ulangan blok untuk soal materi operasi himpunan.

Rendahnya hasil belajar siswa tidak terlepas dari factor intern maupun ekstern. Setiap peserta didik memiliki keunikanya sendiri-sendiri dalam pola adaptasi maupun pola pembelajaranya. Salah satu faktor intern yang dapat mempengaruhi hasil belajar siswa adalah tipe kepribadian siswa. Keirsey (1984) seorang professor dalam bidang psikologi dari California State University menggolongkan kepri-badian menjadi 4 tipe, yaitu Guardian, Artisan, rational dan Idealist. Peng-golongan ini didasarkan pada bagaimana seseorang memperoleh energinya (Extrovert atau Introvert), bagaimana seseorang mengambil informasi (Sensingatau Intuitive), bagaimana seseorang mengambil keputusan
(Thinking atau Feeling) dan bagaimana gaya dasar hidupnya (Judging atau Perceiving). Tentunya masing-masing tipe kepribadian tersebut akan mempunyai karakter berbeda dalam memecahkan permasalahan.

Jigsaw merupakan model pembelajaran kooperatif yang menitik beratkan kepada kerja kelompok siswa dalam bentuk kelompok kecil seperti yang diungkapkan Lie (1993:73) bahwa pembelajaran kooperatif model jigsaw merupakan model belajar kooperatif dengan cara siswa belajar dalam kelompok kecil yang terdiri atas 4-6 orang secara heterogen dan siswa bekerja sama saling ketergantungan positif dan bertanggung jawab secara mandiri. Seperti yang dikemukakan oleh Cagatay \& Demircioglu (2013:31)

The cooperative learning is described as a method where students work together in small mixed groups and help each other for a common academic aim, develop communication abilities, increase problem solving and critical thinking abilities and take an active part own learning.

Pendapat diatas menjelaskan bahwa pembelajaran kooperatif dapat meningkatkan kemampuan pemecahan masalah dan kemampuan berpikir kritis dalam pembelajaran. selain itu Johnson\&Johnson, 2005: Sahin, 2010 dalam Tran (2014) menyatakan bahwa

One alternative teaching method to lecturebased teaching is jigsaw grouping a kind of cooperative learning method. This approach has been claimed to minimize the competitiveness in the learning environment by encouraging students $t$ work together. In addition it is claimed to promote more positive student attitudes toward their own learning, enhance more positive 
relationships between participants, develop self-esteem and cohesiveness and improve learning skill.

Model pembelajaran jigsaw ini siswa memiliki banyak kesempatan untuk mengemukakan pendapat dan mengolah informasi yang didapat dan dapat meningkatkan keterampilan berkomunikasi, anggota kelompok bertanggung jawab atas keberhasilan kelompoknya dan ketuntasan bagian materi yang dipelajari dan dapat menyampaikan kepada kelompoknya (Rusman 2008: 203). Menurut Rusman (2008:205) model pembelajaran jigsaw ini dikenal juga dengan kooperaif para ahli. Karena anggota setiap kelompok sama, kita sebut sebagai team ahli yang bertugas membahas permasalahan yang dihadapi. Selanjutnya, hasil pembahasan itu dibawa kekelompok asal dan disampaikan pada anggota kelompoknya.

Keunggulan model jigsaw menurut Anita (2008: 69) yaitu guru dapat memperhatikan skemata siswa atau latar belakang pengalaman siswa, dapat membantu siswa mengaktifkan skemata agar bahan pelajaran menjadi lebih bermakna, terjalinya suasana gotong royong, banyaknya kesempatan mengolah informasi dan meningkatnya keterampilan berkomunikasi. Selanjutnya Soegeng (2002: 50) menjelaskan Puzzle yaitu kegiatan menyusun potongan-potongan gambar. Potongan-potongan gambar ini selanjutnya akan disusun dalam sebuah peta (map) yang akan dipajang di ruangan kelas. Permainan puzzle akan mampu meningkatkan ketertarikan siswa dalam belajar matematika sehingga peserta didik tidak akan bosan dalam kegiatan pembelajaran. Penggunaan model jigsaw dimana beberapa siswa menjadi ahli yang tersebar di berbagai kelompok dapat melatih siswa dengan kemampuan lebih tidak hanya dapat menyerap pelajaran dan meningkatkan prestasinya sebagai individu tapi juga mampu berkomunikasi dengan baik dalam kelompok. Siswa yang menjadi anggota kelompok juga dapat leluasa bertanya pada siswa ahli jika terdapat kesulitan dalam pemecahan masalah. Hal ini senada dengan yang disampaikan oleh Francis Hul Adam:

There can be some obtacles when using the jigsaw technique. One common problem is a dominant student. In order to reduce this problem, each jigsaw group has an appointed leader. Student realize that group is more effective if each student is allowed to present his or her own material before questions and comments are made. Dominance is eventually reduced because student realize it is not in the best interest of the group.

Puzzle map dapat membantu siswa berkomunikasi aktif menyusun kerangka pemecahan masalah dan menunjukkan hasil kerjanya di display kelas. Hal ini senada dengan yang dipaparkan oleh Soegeng (2002 : 51) yang menerangkan bahwa kelebihan permainan puzzle yaitu selain dapat menyenangkan siswa, jenis permainan ini mengajak mereka untuk berpikir kreatif, aktif, suasana kelas bergairah adanya interaksi siswa dengan guru, siswa dengan siswa dan menciptakan hubungan sosial yang baik.

Penerapan model pembelajaran jigsaw puzzle map memiliki beberapa langkah-langkah (1) siswa dikelompokkan dengan 4 orang anggota, (2) tiap orang diberi materi dan puzzle map yang sama tapi dengan LKS yang berbeda (3)Anggota dari tim yang berbeda dengan penugasan yang sama membentuk kelompok baru (kelompok ahli), (4) setelah kelompok ahli selesai berdiskusi, tiap anggota kembali ke kelompok asal dan menjelaskan kepada anggota kelompoknya tentang subbab yang 
mereka kuasai (5) tiap kelompok asal mempresentasikan hasil diskusi yang telah disusun dalam bentuk puzzle, (6) Pembahasan, (7) penutup dan pendisplay-an hasil kerja diruang kelas.

Beberapa penelitian yang telah dilakukan dan relevan dengan penelitian ini adalah penelitian yang dilakukan oleh Doymus (2008) infestigated the effect of jigsaw technique and instructional teachercentered teaching method on university students attitude to written expression course, their academic retention and their views. Hasil dari penelitian ini adalah siswa yang diberikan teknik jigsaw dalam pembelajaran lebih sukses dibandingkan tanpa jigsaw.Selanjutnyapenelitian yang dilakukan oleh Susanti dan Maharani (2016) mahasiswa dengan tipe kepribadian Guardian, hanya melakukan proses asimilasi dalam memahami masalah, sedangkan tipe Artisan dan Rational dan idealist sudah melakukan proses asimilasi dan abstraksi.

Berdasarkan uraian diatas, maka model jigsaw puzzle map dapat diterapkan pada pembelajaran matematika pada konsep himpunan karena materi himpunan memungkinkan guru menyusun beberapa contoh tentang himpunan kemudian siswa mengklasifikasikan contoh tersebut termasuk dalam himpunan yang mana. Selain itu akan dilihat kemampuan individu dalam menyelesaikan persoalah jika dilihat dari tipe kepribadianya, karena selain factor dari luar yakni model pembelajaran yang diterapkan oleh guru juga terdapat faktor internal yang berperan dalam penentuan prestasi belajar siswa. Secara rinci penelitian difokuskan pada: (1) apakah terdapat perbedaan belajar siswa dengan model pembelajaran jigsaw puzzle map dengan siswa yang diberikan model pembelajaran konvensional pada materi himpunan siswa kelas VII MTsN se Bojonegoro?, (2) apakah terdapat perbedaan prestasi matematika pada masing-masing tipe kepribadian Guardian, Artisan, rational dan idealis terhadap prestasi belajar matematika pada materi himpunan siswa kelas VII MTsN se Bojonegoro?, (3) apakah terdapat hubungan antara model pembelajaran dan tipe kepribadian terhadap prestasi belajar matematika pada materi himpunan siswa kelas VII MTsN se Bojonegoro?

\section{METODE}

Penelitian yang dilakukan adalah penelitian eksperimental semu (quasi experimental research). Manipulasi variabel dalam penelitian ini dilakukan pa-da variabel bebas yaitu Model pembelajaran jigsaw puzzle map untuk kelas eksperimen dan konvensional untuk kelas kontrol. Variabel bebas lain yang ikut mempengaruhi variable terikat adalah tipe kepribadian Guardian, Artisan, rational dan Idealist. Sedangkan waktu penelitianya pada semester genap yaitu tahun pelajaran 2014/2015. Populasi dalam Penelitian ini adalah siswa kelas VII semester genap MTsN 1 Bojonegoro tahun pelajaran 2014/2015 sebanyak 256 siswa yang terbagi menjadi 7 kelas. Pemilihan sampel menggunakan Cluster random sampling. Sampel dalam penelitian ini siswa kelas VII C sebanyak 36 siswa (kelas eksperimen) dan kelas VII D sebanyak 36 siswa (kelas kontrol). Metode pengumpulan data menggunakan metode tes dan dokumentasi. Instrumen yang digunakan berupa tes objektif materi Himpunan dan angket tipe kepribadian siswa.

Uji coba instrument dilakukan di MTsN I Bojonegoro dengan responden 32 siswa kelas VII-A. Instrumen tes hasil belajar mengacu pada kriteria validitas isi, 
daya pembeda ( $\mathrm{D} \geq 0,3)$, tingkat kesukaran $(0,25 \leq \mathrm{P} \leq 0,75)$, dan reliabilitas $\left(r_{x y}>\right.$ 0,70 ) untuk instrumen angket kepribadian digunakan validitas isi, dan untuk menghitung reliabilitasnya digunakan teknik alpha. Dari 35 butir soal tes prestasi yang diujicobakan diperoleh 25 butir soal yang baik, sehingga dapat digunakan sebagai instrumen penelitian tes prestasi belajar matematika siswa. Sedangkan untuk angket dari 40 pertanyaan yang diajukan seluruhnya valid dan reliable dengan beberapa pembenahan dari validator.

Sebelum melakukan penelitian, terlebih dahulu dilakukan analisis data meliputi uji prasarat analisis dan uji keseimbangan. Uji prasarat dalam penelitian ini meliputi uji normalitas dan uji Homogenitas, uji normalitas menggunakan Lilliefors sedangkan untuk uji homogenitas menggunakan Bartlett dan uji keseimbanga menggunakan uji t dua pihak.

\section{HASIL DAN PEMBAHASAN}

Dari hasil uji normalitas dan uji homogenitas sebelum perlakuan menunjukkan bahwa kedua kelompok berdistribusi normal dan memiliki variansi sama. Selanjutnya dilakukan uji keseimbangan, hasilnya kedua kelompok mempunyai kemampuan awal sama. Sebelum dilakukan perlakuan sebelumnya disebarkan angket untuk mengklasifikasikan tipe kepribadian siswa yang selanjutnya dikelompokkan dalam tipe kepribadian Guardian, Artisan, Idealist maupun rasional. Rangkuman hasil angket tipe kepribadian sebagai berikut:

\section{Tabel}

1.RangkumanHasilAngketTipeKepribadianSiswa

\begin{tabular}{cccc}
\hline $\begin{array}{c}\text { Tipe } \\
\text { Kepribadian }\end{array}$ & VII C & VII-D & jumlah \\
\hline Guardian & 12 & 10 & 22 \\
\hline Artisan & 10 & 12 & 22 \\
\hline Idealist & 7 & 8 & 15 \\
\hline Rational & 6 & 5 & 11 \\
\hline
\end{tabular}

jumlah $\quad 35 \quad 35$

\section{SIMPULAN}

Berdasarkan hasil penelitian dan analisa data yang telah dilakukan, maka dapat disimpulkan sebagai berikut :

1. Siswayang diberikan model pembelajaran Jigsaw Puzzle map mempunyai prestasi belajar matematika yang lebih baik daripada siswa-siswa dengan pembelajaran konvensional.

2. Prestasi belajar matematika siswa yang mempunyai Tipe Kepribadian Guardian lebih baik daripada prestasi belajar matematika siswa yang mempunyai tipe kepribadian Artisan, rational maupun Idealist. Begitu juga pada siswa yang memiliki tipe kepribadian Rational lebih baik prestasinya daripada siswa dengan tipe kepribadian artisan dan Idealist. Sedangkan siswa dengna tipe kepribadian Artisan dan Idealist memiliki prestasi belajar matematika yang sama.

3. Tidak terdapat interaksi antara siswa yang diberikan model pembelajaran Jigsaw Puzzle Map maupun Konvensional dengan tipe kepribadian siswa yaitu tipe Guardian, Artisan, Rational dan Idealist.

\section{DAFTAR PUSTAKA}

Anita Lie. 2008. Cooperative Learning: Mempraktikan Cooperative Learning di Ruang-Ruang Kelas. Jakarta: Grasindo

BNSP. 2006. Permendiknas RI No.22 tahun 2006. Tentang standart isi untuk satuan Pendidikan dasar dan menengah. Jakarta 
Cagatay, Gulsen \& Demircioglu, Gokhan. 2013. The Effects of Jigsaw-i Cooperative Learning Technique on Students' Understanding About Basic Organic Chemistry Concepts. The International Journal of Educational Researches. 4(2): 30-37

Doymus, Kemal. 2008.Teaching Chemical Equilibrium with the Jigsaw Technique. Research in Science Education. 38(2): 249-260

Elin Driana.2012. gawat darurat Pendidikan diterbitkan kompas.com pada 14 desember 2012

IEA. 2012. TIMSS 2011 international results in mathematics.[online]. Tersedia: http://timss.bc.edu.timss2011/downl oads/T11_IR_M_chapter1.pdf [28

Kiersey, David. 2010. overview Temperaments. Diunduh dari www.keirsey.com

Kompas. 2013. Posisi Indonesia Nyaris Jadi Juru Kunci. (online). tersedia: http://www.kopertis12.or.id/2013 /12/05/skor-pisa-posisiindonesia-nyaris-jadi-jurukunci.html.
Rusman. 2008.Model-Model Pembelajaran: Mengembangkan Profesionalisme Guru (Edisi 2). Jakarta: RajawaliPers

Soegeng Santoso. 2002. Pendidikan Anak

Usia Dini. Jakarta: Citra

Pendidikan Indonesia

Susanti \& Maharani. 2016. Profil Berpikir Mahasiswa dalam Memecahkan Masalah Numerical Analysis Ditinjau dari Tipe Kepribadian. JurnalFormatif 6(1): 62-72

Tran, Van Dat. 2014.The Effects of Cooperative Learning on the Academic Achievement and Knowledge Retention. International of Higher Education. 3(2): 131-140

Whyte, Julie \& Anthony, Glenda. 2012.Math Anxiety : The Fear Factor in the Mathematics Classroom.New Zaeland Journal of Teachers' Work. 9(1):6-15 